\title{
The Durban University Of Technology's Experiences Of Open Educational Resources
}

A. D. van der Merwe, Durban University of Technology, South Africa

\begin{abstract}
There seems to be growing confidence that the open education movement is set to reshape the higher education landscape. Perhaps the single most formidable challenge retarding the uptake of open education resources (OERs) is instructors' lack of knowledge and experience of these materials. This descriptive case study examines the experiences Durban University of Technology (DUT) faculty have of OERs. As such, it lays the groundwork for subsequent studies of the attitudes of faculty to OERs and to the philosophy of open education. It also interrogates the national and institutional policy environment to establish to what extent these foster a culture of sharing and openness in local higher education. The findings reported here may thus provide a context for understanding the attitudes of DUT faculty to OERs (examined in a separate study) and may serve as useful indicators of how the university is positioned; that is, how deep its foundations are, with respect to its prospects of participating successfully in the higher education OER movement.
\end{abstract}

Keywords: Open Education; Open Education Resources; Open Educational Resources; Higher Education

\section{INTRODUCTION}

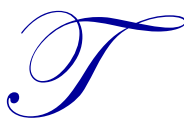

he worldwide movement toward Open Educational Resources (OER) is inspired by the powerful notion that the world's knowledge is a public good and that technology, in general, and the internet, in particular, offer an extraordinary opportunity to share, use, and reuse knowledge (Breck, 2007). Other intuitions on which the OER movement is based are that it should be easy to collaborate, individuals should receive credit for their contributions, and concepts and ideas are linked in unexpected ways, not necessarily the simple linear forms presented in contemporary standard textbooks. Baraniuk and Burrus (2008) contend that OERs promise to fundamentally change the way authors, instructors, and students interact worldwide.

The potential benefits of OERs are widely recognised. These include, among others, cost reductions, widening participation in higher education by expanding access to non-traditional learners, promoting lifelong learning, bridging the gap between formal and informal learning and leveraging tax revenue by sharing knowledge (Hodgkinson-Williams, 2010). There is also the important consideration that the peer review process inherent to the process of opening up resources may result in improved teaching and learning materials.

The term "Open Educational Resources" was used for the first time at the United Nations Educational, Scientific and Cultural Organisation's (UNESCO) 2002 Forum on the Impact of Open Courseware for Higher Education in Developing Countries. OERs are the products of a worldwide internet-empowered community whose objective is to help equalise access to knowledge and educational opportunities. OERs comprise teaching, learning and research resources that reside in the public domain or have been released under intellectual property license that permits their free use and customisation by others. Breck (2007) notes that it is the granting of freedoms to share, reprint, translate, combine and adapt resources that makes them educationally different from those that can only be read online at no cost. For the purposes of this study, OERs include open courseware and content, open software tools (e.g. learning management systems such as Moodle), open material for e-learning capacity building of teaching staff, repositories of learning objects, and free educational courses. 
In spite of the considerable challenges that the open educational movement faces, there seems to be growing confidence that this movement is set to reshape the higher education (HE) landscape (Carey, 2012; Duncan, 2012). Perhaps the single most formidable challenge retarding the uptake of OERs is instructors' lack of knowledge and experience of these resources. Knowledge and experience must inform attitudes (which should properly be the subject of a separate study) and it is peoples' attitudes that will determine whether, and to what extent, they will embrace new relationships, ideas, concepts, and philosophies.

Against the background of a general dearth of studies of South African HE OER experiences, this paper, on a case study basis, examines the experiences Durban University of Technology (DUT) faculty have of OERs. As such, it lays the groundwork for subsequent studies of the attitudes of faculty to OERs and to the philosophy of open education. It also interrogates the national and institutional policy environment to establish to what extent these foster a culture of sharing and openness in higher education. The findings reported here may thus provide a context for understanding the attitudes of DUT faculty to OERs (examined in a separate study) and may serve as useful indicators of how DUT is positioned; that is, how deep its foundations are, with respect to its prospects of participating successfully in the HE OER movement. It is possible that the findings of this study may provide some useful insight, particularly for other local tertiary education institutions.

\section{REVIEW OF THE LITERATURE}

\section{What are OERs?}

In 1998, Wiley, inspired by Raymond and Perens's open source software initiative in the same year, established the "open content" brand (Wiley and Gurrell, 2009). Wiley's open content philosophy, in respect of educational and other content, is based on Raymond and Perens's arguments advocating the benefits of open source software. Bissel and Boyle (2007) note that the OER movement constitutes an effort to transform the conditions of teaching and learning by advocating the power of resources that invite collaboration and that enable contributions to be combined, disassembled and shared.

Hilton et al. (2010) note that several definitions of OERs have been offered. An early UNESCO (Anon., 2002) definition states that OERs are educational resources, enabled by information and communication technologies for consultation, use and adoption by a community of users for non-commercial purposes. D' Antoni (2009) notes that definitions have progressed from an initial description of the material to include tools needed to support OERs and eventually to a philosophy. Hilton et al. (2010) note that the construct of "openness" is rich and multidimensional and has thus far eluded rigid definition in the literature. It seems safe to conclude, however, that a key common feature of all OERs is that "open" means that they are freely available for use by educators and students without the need to pay royalties or licence fees (Butcher, 2010).

Hilton et al. (2010) note that the various degrees of openness of OERs are indicated by the four "Rs" that specify the uses that an OER formally permits by its licence. The four Rs include reuse, redistribute, revise and remix. "Reuse" allows free use of all or part of the unaltered, verbatim work and is the most basic level of openness. "Redistribute" allows individuals to share copies of the work, while "revise" permits material to be adapted, translated or otherwise modified. "Remix" allows individuals to create new derivative resources by combining two or more existing resources. Hilton, et al observe that open licences are necessary for defining the usage rights attached to OERs since many countries have statutes that enforce copyright in respect of reusing creative works. The most popular framework governing the licensing of OERs is that offered by Creative Commons. The various Creative Commons licences specify the rights of usage indicated by the four Rs that define the degree of openness of particular OERs.

The term "resource" in OER is relatively more easily defined. Yuan, Macneill, and Kraan (2008) note that OERs include, but are not limited to, learning content, tools, and implementation resources. Learning content may include, among others, full courses, content modules, collections, and journals. Tools could comprise software to aid the development, use and reuse and delivery of content via course and learning management systems, content development tools, and online learning communities. Implementation resources include intellectual property licences to promote publishing of materials, design principles of best practice, and localise content. 


\section{Potential Of Open Education}

While questions may persist about what exactly constitutes an OER, the promise of OERs, on the other hand, is more certainly documented in the literature. Although the potential benefits of these resources have social, pedagogic, and economic dimensions, the concept of open education also has a humanitarian appeal. Caswell, et al. (2008) note the argument advanced by many that free and open access to education is a basic human right - a notion that is rendered more compelling from an ethical point of view if educational materials can be electronically copied and transferred around the world at almost no cost.

The Open e-Learning Content Observatory Services (OLCOS) Roadmap (Geser, 2007) lists various general, anticipated benefits of open educational resources. These include:

- $\quad$ Higher returns on public funds invested in education through improved cost-effectiveness when reusing resources (e.g. sharing development costs among institutions or professional communities)

- The creation of networks for the production and sharing of educational resources based on a strong emphasis of re-usability

- $\quad$ Enriching the pool of resources (content and tools) for redesigning curricula and improving teaching and learning practices without the need to worry about copyright issues

- $\quad$ Promoting digital competence for the knowledge society beyond basic information and communication technology (ICT) tools and content that allow learners to develop their critical thinking and creative faculties

Other possible benefits of OERs include the prospect of leveraging the educational quality of content through quality control, feedback, and improvements within content alliances, communities, and networks who share content. Furthermore, open education may promote lifelong learning and social inclusion through easy access to resources that might otherwise not be accessible.

\section{Review Of Some OER Initiatives}

A burgeoning number of OER projects worldwide suggest that the promise of OERs and open education is not without foundation. Butcher (2010) lists several notable global HE OER initiatives, including the OpenCourseWare (OCW) Consortium which focuses on developing and sharing freely available, stand-alone, online course, and teaching materials. There are currently over 2,500 open courses available from over 200 universities around the world which can be accessed via the OCW website. The Multimedia Educational Resource for Learning and Teaching Online (MERLOT) is a similar initiative which provides free and open resources designed primarily for faculty and students of higher education. MERLOT permits users to access more than 22,500 peer-reviewed online teaching and learning materials and share advice and expertise about education with expert colleagues.

In China, 451 courses have been made available by 176 university members of the China Open Resources for Education consortium. In Japan, 1,500 courses have been made available by universities participating in the Japanese OCW Consortium. In France, more than 2,000 educational resources from around 200 teaching units have been made available by twelve member universities of the ParisTech OCW project. In the United Kingdom (UK), there are several higher education OER initiatives of which two are especially notable. The first of these is JORUM, a free online repository service for teaching and support staff in United Kingdom Further and HE Institutions. The second is a well-known institutional source of HE OERs - OpenLearn (The Open University), one of the world's most successful distance education universities.

Butcher notes that the Massachusetts Institute of Technology (MIT) has perhaps the most high profile OCW project and has inspired many colleges from around the world to get involved in the open education movement. The university currently makes available 2,100 courses via its OCW site at no cost for non-commercial purposes. Butcher reports MIT's experience of finding that this process of sharing materials has resulted in significant increases in shared use of content within its own institution as departments increasingly source materials from each other rather than developing their own from scratch. Another American OER initiative is Rice University's online Connexions project which offers 20,000 modules woven into 1,217 collections. 
African HE OER offerings include the University of Western Cape's OCW initiative and the University of Cape Town's Open Content UCT which allows users to access open teaching and learning content from the University of Cape Town (UCT). OER Africa is an initiative of the South African Institute for Distance Education (SAIDE) and is involved in promoting the use of OER in Africa and supporting individuals and organizations in creating OER.

\section{What Experiences Have OER Initiatives Afforded?}

It is worth reviewing specific OER projects at a micro level to ascertain the experiences of individuals. Unfortunately, the literature records only a few of the findings of such studies which in fact inspired this particular study. Wiley (2006) confirms that generally there has been little analysis of OER use. He notes the following broad patterns of OER use recorded by an American university:

- Individuals who are neither teachers nor students in formal programmes access OERs mainly for personal reasons.

- $\quad$ Students accessing OERs do so mainly for personal reasons, to complement their courses, or to plan their studies.

- Instructors employ OERs primarily to plan or prepare a course, enhance their personal knowledge, or learn about topics related to their research.

The OER experiences of some other countries may provide further insight.

South Africa

Sapire and Reed (2011) report the findings from a case study of a collaborative OER development project initiated by SAIDE. In this project (ACEMaths), mathematics teacher educators from nine tertiary institutions collaborated in designing OER for mathematics teacher education courses. The study tried to establish whether the collaborative redesigning of existing materials could improve quality given time and cost constraints and whether such collaboration encourages teacher educators and students to embrace OERs.

Sapire and Reed note that, among other benefits, the teacher educators appreciated the opportunities that OERs afforded for independent study and instructor learning. The quality of materials was rated as good as, and often better, than prescribed textbooks and reportedly injected a high level of flexibility into the teaching and learning process. Furthermore, respondents stated that the OERs facilitated a problem-solving instructional approach with diverse learner groups. Sapire and Reed consider that the ACEMaths project spawned a community of practice in bringing together teacher educators who might not otherwise have had an opportunity to collaborate in developing and using OERs. They suggest that the project provided a setting within which participants could identify common problems, share ideas, offer their experiences, explore new possibilities, build understandings and insight, and create new mutually beneficial educational products and approaches.

In spite of the project's clear benefits, Sapire and Reed observe that, by 2009, the community had reportedly become much less active and communication among its members had decreased. This development is suggestive of challenges that commonly plague OER initiatives. Some of the obstacles to OER creation and use cited by respondents include communication breakdowns between collaborators, limited student access to computers, and logistical and time constraints. Additionally, some of the participants, as well as senior managers in their HE institutions, were not clear on the full range of permissions granted under Creative Commons licences and this fact would have slowed OER collaboration and uptake.

Sapire and Reed note that where there was institutional support for using OERs, this was likely to lead to higher levels of take-up. In addition, lecturers who enjoyed the flexibility to work independently, and with a measure of freedom, were more likely to use and adapt the OER. Conversely, in institutions where staff were required to conform, or forced to work with colleagues who were unwilling to change, the lecturers who had engaged in the OER design process needed more time and had to go to greater lengths to convince colleagues to use the OER. 
In 2005, the University of Cape Town introduced its open source content and collaboration software - Vula - which is used by the institution as a repository of teaching, learning, supervision, and research resources. Hodgkinson-Williams (2009) notes that $47 \%$ of staff member respondents indicated that they used OERs produced by other universities for academic purposes and 33\% for personal use. She posits that this suggests some awareness of OERs but that further study is required to establish what resources faculty are using and how they are integrating these materials into their teaching. Of student respondents, $44 \%$ indicated that they used OERs for study purposes, $31 \%$ stated that these materials were put to personal use, and 31\% responded that they did not use OERs at all.

\section{Netherlands}

Schuwer and Mulder (2009) discuss the findings of a Dutch university's experiment in which Open Educational Resources (OER) were offered in an attempt to bridge the gap between informal and formal learning and to establish a barrier-free entry portal to higher education. They observe that some of the university's schools were hesitant to be involved with the project citing workload and time constraints. However, once the OER online site was launched in 2006, it attracted 25,000 visitors during the first week. Toward the end of 2008, the site was recording 800 hits per day with a total of 750,000 visitors since inception, of which $12 \%$ were return visitors.

In 2008, the university had 24 courses available on its website which were all published under a Creative Commons licence (Attribution, Non-commercial, Share Alike). Schuwer and Mulder note that the format employed to deliver courses ranged from text only (in downloadable PDF files) to fully web-based and highly interactive (such as games). Some courses included a video podcast of a presentation and a study guide for a book. Where intellectual property rights were asserted, parts of certain courses were published under a more restrictive licence. In other instances, authors of copyright material were compensated so that their material could be published as part of the OER under Creative Commons licence. In 2008, the costs of producing the various OERs ranged from $€ 3000$ (for a course derived from an existing regular university course, delivered as PDF files) to $€ 30,000$ (interactive material such as games). The university offered five courses in 2008 with the option of examination and accreditation for a service fee of €50. Approximately 85 students availed themselves of this opportunity. Of the users of the university's OER site, $9 \%$ stated that they went on to enrol in its formal programmes.

\section{Mauritius}

Issack (2011) reports the University of Mauritius experience of its Virtual Campus which was launched with the objectives of increasing access to education in the country and promoting innovative teaching and learning on the university campus. Due to limited funds and resources, the university was forced to employ cost effective methods to sustain the Virtual Campus. One such strategy was to deploy Open Source Tools and Techniques in its delivery of education. Notwithstanding this, notes Issack, the cost of developing content still proved prohibitive. This problem was surmounted to some extent by external funding and also by using OERs to reduce the cost of development of courseware. This approach afforded the university some leeway to reduce some tuition fees with the expectation that total enrolments would probably increase in the future.

The virtual campus project experience was not without its challenges. Issack notes that the responses from faculty to the OER workshops and presentations were generally lukewarm. He suggests various possible reasons for this, including tight work schedules and a preference among academics to focus on research rather than teaching. Furthermore, faculty were probably sensible of the fact that the university offered no incentive or recognition for their involvement in the virtual campus project. Issack suggests further that faculty are generally not comfortable with the prospect of operating beyond their comfort zones of traditional classroom settings and may resent the effort required to master and assimilate content produced by others.

Confusion over copyright issues and concerns over the quality of OERs may also have created some tacit resistance from faculty to the virtual campus project. Issack reports that some academics regarded material they had produced as their intellectual property. Others, on the other hand, pointed out that under employment and copyright laws, the employer retains copyright of the materials unless the employment contracts state otherwise. Faculty wanted some assurance/authentication of the quality of downloadable OERs. They also wanted to know what additional skills and training in OER design/use would be required for academics of different fields who have 
limited knowledge of information technology, and instructional design. A corollary to this requirement was a concern about the level of support and encouragement/incentives that faculty could expect for their involvement in OER design.

\section{Copyright Challenges}

One of the most formidable challenges facing OER initiatives is that of inadequate copyright legislation. Ncube (2011) notes the finding that in none of the eight African countries (including South Africa) that were investigated did copyright laws facilitate meaningful access to learning materials generally. An unfortunate consequence of these inadequacies in the law, and the prevailing socio-economic conditions, is that copyright law is often ignored and access to learning materials is consequently obtained illegally.

Ncube suggests that educational institutions should benefit from exploring the use of openly licensed educational content (OERs) since this would bypass current legislative shortcomings. She recommends, in addition to using existing OERs, that HE institutions consider producing more of these materials in order to further build the open education community. Ncube cautions that the production of OERs should be supported by significant institutional policy and practice shifts, such as establishing the necessary copyright clearance procedures. Should new OERs incorporate copyright-protected material, the permission of the copyright holder must be obtained. Ncube warns against the temptation to exclude critical copyright material on which good quality OERs may depend since this could ultimately damage the institution's reputation.

\section{Policy Issues}

Some of the negative open education experiences of HE institutions and copyright concerns suggest that government and higher education policy is key to creating an environment that is conducive to successful OER development and propagation. The South African government's recent Green Paper for Post-School Education and Training (Department of Higher Education and Training, 2012) recognises the pedagogic and economic attractions of OERs in conceding that 'hoped for' improvements in quality and cost savings in rolling out education are strong motivations for including open education as a key aspect of its policy framework.

Since the bulk of OERs are released in digital format and released/accessed online, one should not ignore the vital issue of the extent of "openness" of ICTs. The National Advisory Council on Innovation Open Software Working Group (Anon., 2004) noted that South Africa was the first African nation to follow the example of many others in adopting free and open source software (FOSS) policies. Its decision to follow this route was based on cost/performance criteria that favoured FOSS. Subsequently, revised government policy in respect of FOSS recognises that it can contribute in meaningful ways to economic development, generally, while directly supporting South African economic development priorities, in particular.

Significant aspects of current government policy in respect of FOSS include the following:

- Government will implement FOSS unless proprietary software is significantly superior. In cases where FOSS and its proprietary equivalents have similar technical merits, FOSS solutions will be implemented.

- $\quad$ Government will migrate current proprietary software to FOSS where possible.

- $\quad$ All new software developed for government will be based on open standards and should adhere to FOSS principles.

- $\quad$ Government will ensure that all government content and content developed using government resources is made Open Content unless it is demonstrated that proprietary licensing or confidentiality is substantially beneficial.

- $\quad$ Government will encourage the use of Open Content and Open Standards within South Africa.

It is unclear, at this juncture, how national policy has affected the ICT decisions of the country's publicly funded education institutions. 
Institutional policy is similarly likely to influence the uptake of OERs (Wilson, 2008). DUT has no formal policy on open education or OERs, although it is committed to the spirit of "Open Access". Muller et al. (2011) note that a common thread running through most definitions of Open Access is the reference to research, information and literature that is in digital format, available online, free of charge, and free of most copyright and licensing restrictions. DUT has indicated its intention to adopt an open access approach to developing its institutional repository (IR), although, according to Muller et al., this intent has not been formalised by way of policy. The purpose of the IR is to manage, preserve, and provide electronic access to the intellectual research output of staff and students of the institution.

It is quite likely that any concerns that DUT and its faculty may have about Open Access extend equally to open educational resource initiatives and could account for the apparent caution of the institution in engaging in such projects. Indeed, a potentially complicating factor for faculty wanting to develop open education resources is that of copyright issues and confusion about the rights that open licences grant. Thus, even if faculty are willing to open licence their work, they are contractually bound to recognise DUT's intellectual property rights claimed in respect of materials developed by its employees. This is a problem experienced by other South African universities considering open educational initiatives (Hodgkinson-Williams, 2009). Notwithstanding this, certain departments of the university seem keen to "open up". Thus, for example, the institution's library is investigating ways of distributing Libre Office to students, a FOSS equivalent of Microsoft Word (Mitha, 2012). This study examines what other open education experiences DUT faculty, across all of its faculties and departments, may be able to share.

\section{METHOD}

\section{Population Characteristics}

This case study was based on an online survey of DUT faculty across its five campuses, six faculties, the Centre for Excellence in Teaching and the Learning and the Business Studies Unit. The population of permanent and contract academic staff at the time of the survey (2011) was 585 and comprised slightly more males (313) than females. The average age of faculty was 46.23 years and the median age 45.63 . The average number of years of service was 14.21 and the median years of service was 13.55 . Faculty with doctorates constituted $12 \%$ of the population while $43 \%$ had a Master's degree.

\section{The Survey Instrument}

The electronic questionnaire comprised a general section in which some biographical information was elicited and also a section dealing with open educational resources in the classroom. The entire questionnaire comprises 24 items that are a mix of written, multiple choice and five-point Likert scale questions. The questionnaire was administered in the second half of 2011 with a follow-up invitation to faculty to participate in the survey about a month after the first invitation. A total of 80 responses were received (50 full and 30 partially completed questionnaires). The questionnaire did not force responses and some respondents, accordingly, may have chosen not to disclose certain information. Even if one question was not answered, the questionnaire was considered to be partially completed. The data supplied in all the questionnaires were analysed.

\section{Sample Characteristics}

Table 1 reflects the frequency distribution of responses received from faculty in DUT's various faculties and units. Only the Business Studies Unit offered no responses. 
Table1: Frequency Distribution Of Responses

\begin{tabular}{|l|c|}
\hline \multicolumn{1}{|c|}{ Faculty/Unit } & \% \\
\hline Accounting and Informatics & 13.75 \\
\hline Applied Sciences & 6.25 \\
\hline Arts and Design & 11.25 \\
\hline Centre for Excellence in Teaching and Learning (CELT) & 5.00 \\
\hline Engineering and Built Environment & 11.25 \\
\hline Faculty of Health Sciences & 13.75 \\
\hline Faculty of Management Sciences & 16.25 \\
\hline Business Studies Unit & 0 \\
\hline Undisclosed & 22.5 \\
\hline
\end{tabular}

The sample comprised more females (48.75\%) than males (37.5\%) and the balance did not disclose this information. The average age of respondents was 43.11 years and the median age 42.5 years. The average number of years of service of respondents was 13.37 and the median was 10 years. The proportion of the sample that is qualified to doctoral level is $8.75 \%$ while $43.75 \%$ have masters degrees and $16.25 \%$ did not volunteer this information. A comparison of the sample and population characteristics would suggest that the former is reasonably representative of the latter.

\section{ANALYSIS}

The open educational resource experiences of faculty should be appreciated in the context of their circumstances. Thus, with respect to their core function of teaching, the average number of students per class taught by respondents was 58 and each respondent was involved in teaching at least one or more levels ranging from first year through to doctoral level studies. Asked to rate the socio-economic background of their students the majority of respondents $(78.75 \%)$ indicated that they were generally in the lower-to-middle income bracket. This is significant considering that a common complaint that faculty have is that their students often do not purchase the prescribed texts. If, in the experience of faculty, students cannot afford study material, this suggests that they may be responsive to the merits of suitable OERs.

When asked whether they use any open educational content in their teaching approach, $57 \%$ of respondents confirmed that they do. The rate of non-response (13\%) in respect of this item may indicate that some respondents may not have been clear about usage rights pertaining to some of the materials they employ. Respondents indicated that, on average, about $20 \%$ of their instructional materials comprised open educational resources as defined in this study. Figure 1 describes the nature of the various resources that were listed for respondents and from which they could make multiple choices. Notes (31\%), exercises/quizzes (31\%), tasks/assignments $(25 \%)$ and other free online content $(29 \%)$ were the most popular materials.

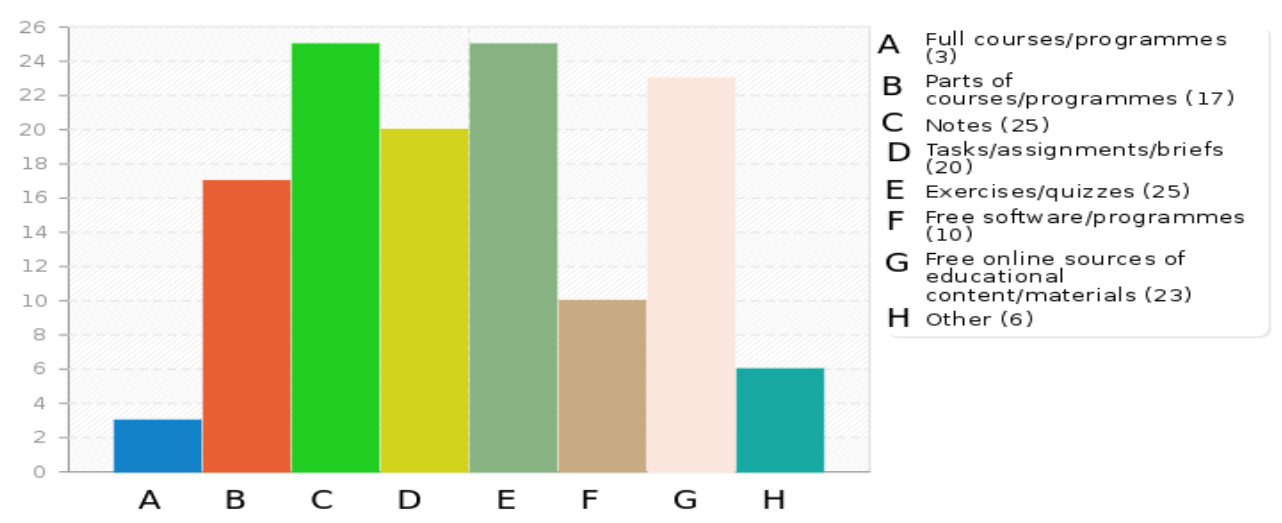

Figure 1: Types Of Open Educational Resources Employed By Faculty 
Table 2 offers some insight into the opinions faculty had of the quality of open educational resources in their respective disciplines. While $62.26 \%$ of respondents stated that the quality of these materials is at least reasonable, the significant non-response in respect of this item, together with those who indicated uncertainty, may be indicative of an element of doubt about OERs. If so, this would be in keeping with the literature which records similar concerns.

Table 2: Perceived Quality Of OERs

\begin{tabular}{|l|c|}
\hline \multicolumn{1}{|c|}{ Opinion Of Quality } & Percent \\
\hline Generally good & 22.64 \\
\hline Reasonable & 39.62 \\
\hline Uncertain & 16.98 \\
\hline Below par (relative to copyright-protected) materials & 0 \\
\hline Poor & 1.84 \\
\hline No answer & 18.87 \\
\hline
\end{tabular}

Since OERs are primarily distributed and accessed online, it is important to gauge the level of comfort of faculty with respect to using ICTs, as well as their confidence in using these tools. Respondents were invited to rate their level of comfort with ICTs on a scale of 0-10, with 0 indicating zero comfort and $10=100 \%$ comfort. The mean level of comfort indicated was 7.8 and the median comfort level was 8 . Respondents were also asked to estimate their proficiency on the same scale. As one might expect, the proficiency scores corresponded closely with the comfort scores (mean $=7.6$, median $=8$ ). These findings suggest that DUT faculty are sufficiently qualified to at least comfortably and proficiently access the bulk of OERs.

While DUT faculty appear to be in a good position to access OERs, there has, until this survey, been no audit of the level of institutional engagement with these materials. Respondents were invited to list the various instructional resources they employ in an effort to determine what space OERs currently occupy in relation to instructors' total stocks of teaching aids. Respondents were invited to identify, from a supplied list, multiple choices of the various types of instructional resources they employ. Figure 2 shows that, although online open educational resources were employed by $30 \%$ of respondents, the most popular materials are those produced by faculty (59\%), prescribed texts (39\%) and library (36\%) sources, all of which have copyright implications. Only $16 \%$ of respondents reported the experience of using materials produced by colleagues. Pending an investigation of the attitudes of DUT faculty to OERs, it remains an open question as to what this indicates about the ethos and culture of sharing and openness at the institution.

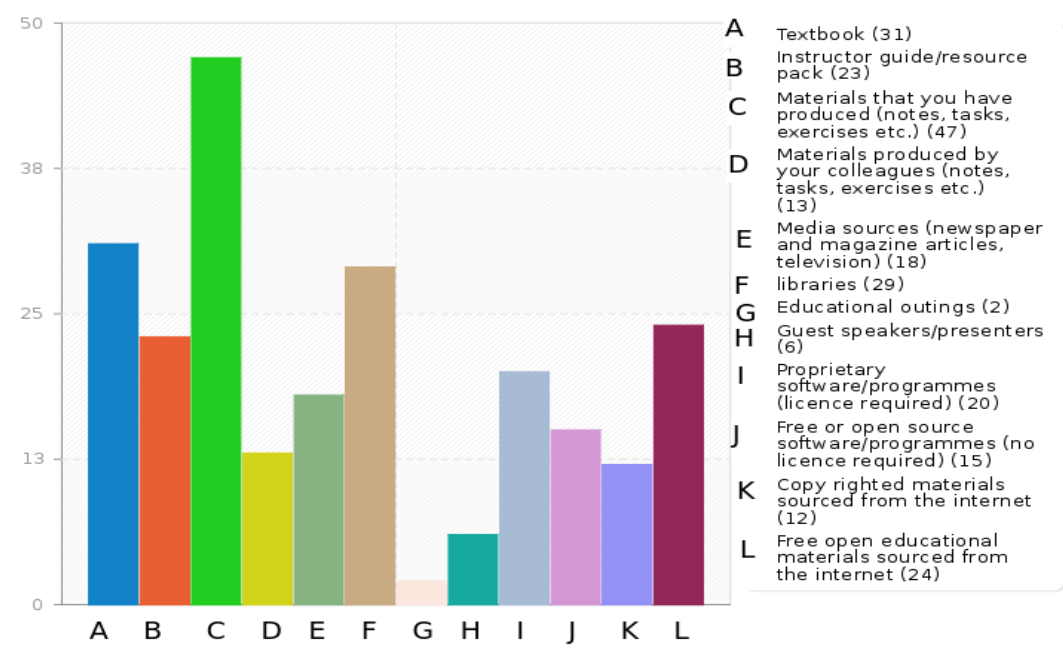

Figure 2: Teaching Resources Employed 
Since the bulk of OERs are accessed via ICTs, it is important to establish the degree of openness of this infrastructure for the purposes of maximum reach. The vast majority of respondents $(65 \%)$ reported that they used the Microsoft Windows operating system and 5\% indicated that they used Apple Mackintosh, both proprietary and closed source products. The relatively high incidence of non-response in respect of this item (30\%) suggests that a significant number of respondents may not have been knowledgeable about the operating system driving their computer/s. No instances of Linux, Ubuntu or other FOSS operating systems were reported. However, if some respondents were indeed not aware of what operating systems they were using, there may be some under-reporting in respect of this category.

Table 3 reveals that $76 \%$ of respondents reported that at least half the software they use, and that they expect their students to use, is also proprietary. Figure 3 shows a frequency distribution of software programmes used by faculty which naturally corresponds closely with programme use by their students. It is noteworthy that established, robust and powerful FOSS equivalents of each of these programmes are used daily in many higher education institutions. Why, then, if the university draws students primarily from income-stressed, lower-to-middle income families, are more of these open resources not employed to ease cost pressures which benefit can be passed on to students? The non-response rate of $13.21 \%$, once again, may suggest the possibility that a considerable number of respondents were not clear about usage rights in respect of the software they use.

Table 3: Software Usage Rights Reported By Faculty

\begin{tabular}{|l|c|}
\hline \multicolumn{1}{|c|}{ Status } & Percent \\
\hline All software used by me and my students is proprietary & 33.96 \\
\hline Most of the software used by me and my students is proprietary & 32.08 \\
\hline About half the software used by me and my students is proprietary & 9.43 \\
\hline Less than half the software we use is proprietary & 5.66 \\
\hline None of the software we use is proprietary & 5.66 \\
\hline No answer & 13.21 \\
\hline
\end{tabular}

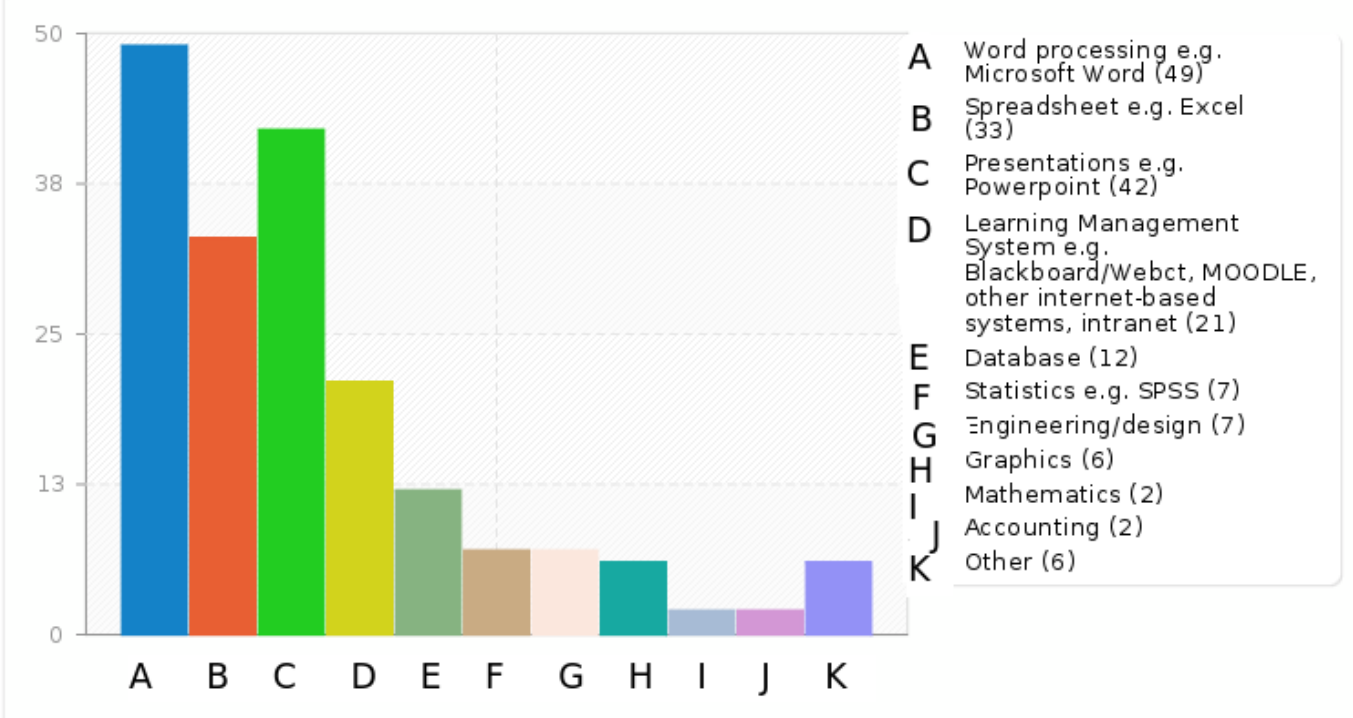

Figure 3: Software Programmes Used By Faculty

The results of various bivariate Chi Square tests of independence suggest that the only statistically significant association between variables identified by this study is that between gender and respondents' tendency to use OERs. Thus, females were more likely than males to employ OERs as part of their instructional designs $(\chi=$ $20.71255, \mathrm{df}=4, \mathrm{p}=0.0003611<0.001)$. Pearson bivariate correlation tests suggested direct relationships between the percent of resources used, which are OERs and ICT comfort and proficiency, although these results were not statistically significant. 


\section{LIMITATIONS OF THE STUDY}

In keeping with its qualitative design, the findings of this study cannot be generalised, with confidence, beyond the single case of DUT. Future similar studies could profitably analyse larger samples across more cases and also examine the attitudes of both instructors and students to OERs.

\section{CONCLUSION}

This study set out to examine the experiences DUT faculty have of OERs with the aim of gauging the institution's state of readiness to participate in the growing open education movement. It established, encouragingly, that more than half of the faculty that participated in the survey stated that they employed OERs as part of their instructional approach. Notes, exercises/quizzes, tasks/assignments and other free online content were the most popular materials. Most respondents felt that the quality of these resources was at least reasonable.

Furthermore, the study established that DUT faculty, on the basis of respondents' self-assessed comfort and proficiency ICT scores, are evidently sufficiently qualified to access the bulk of OERs which tend to be distributed in digital format and online. When asked to indicate their use of OERs alongside other teaching materials, respondents' reported use of these aids fell to $30 \%$. Only 16 percent of faculty reported that they made use of colleagues' resources, which may or may not be an indicator of a lack of openness in DUT's institutional culture.

The study cast further doubt on the university's ethos of openness in education in noting that most of the computer operating systems and programme software it employs are proprietary and closed source. This is unlikely to be helpful in accelerating the uptake of OERs which tend, in the main, to be produced in digital format and disseminated online (even though many OERs are compatible with proprietary ICTs). The cost of proprietary, closed source technologies, which often have perfectly good FOSS equivalents, must inevitably be transmitted to the university's students who are from largely lower-to-middle income backgrounds.

The notable degree of non-response, particularly in respect of items relating to licensing issues with regard to ICTs and software programmes and the relatively low percent of OERs employed by faculty in relation to other teaching materials suggests a lack of confidence in these resources. This circumstance is not helped by the fact that DUT does not have in place a formal policy in respect of open education and open educational resources. Such a policy should, amongst other things, address the issues of intellectual property rights, copyright, and open licensing in order to create an environment that encourages not only the use, but also the production, of OERs.

\section{AUTHOR INFORMATION}

A. D. van der Merwe is a senior lecturer in the Department of Economics at the Durban University of Technology's Riverside campus. He is currently researching the potential of open education resources to boost teaching and learning in local high schools and tertiary training institutions. E-mail: $\underline{\text { alexvdm@dut.ac.za }}$

\section{REFERENCES}

1. Anon. (2002). Forum on the Impact of Open Courseware for Higher Education in Developing Countries (pp. 1-28). Paris: UNESCO. Retrieved from unesdoc.unesco.org/images/0012/001285/128515e.pdf

2. Anon. (2004). Free/Libre \& Open Source Software and Open Standards in South Africa - A Critical Issue for Addressing the Digital Divide (No. 2.6.9) (pp. 1-63). National Advisory Council on Innovation Open Software Working Group. Retrieved from www.gissa.org.za/special-interest-groups/open-source/foss.../file

3. Baraniuk, R. G., \& Sidney Burrus, C. (2008). Global Warming Toward Open Educational Resources. Communications Of The ACM, 51(9), 30-32.

4. Bissel, A., \& Boyle, J. (2007). Introduction to Special Issue on Opening Educational Resources. Educational Technology, 47(6). Retrieved from asianvu.com/.../Educational_Technology_NovDec2007_issue.pdf

5. Breck, J. (2007). Introduction to Special Issue on Opening Educational Resources. Educational Technology, 47(6), 3-5. 
6. Butcher, N. (2010). Open Educational Resources and Higher Education (Dossier) (pp. 1-28). OER Africa, SAIDE. Retrieved from http://www.col.org/SiteCollectionDocuments/OER_Open_Educational_Resources_and_Higher_Education. pdf

7. Carey, K. (2012, January 22). MIT Mints a Valuable New Form of Academic Currency. The Chronicle of Higher Education. Retrieved from http://chronicle.com/article/MIT-Mints-a-Valuable-New-Form/130410/

8. Caswell, T., Henson, S., Jenson, M., \& Wiley, D. (2008). Open Educational Resources: Enabling universal education. International Review of Research in Open and Distance Learning, 9(1), 1-11.

9. D’ Antoni, S. (2009). Open Educational Resources: reviewing initiatives and issues. Open Learning, 24(1), 3-10.

10. Duncan, F. (2012, June). A Harvard education for free (kind of...). Personal Finance, p. 9.

11. Geser, G. (Ed). (2007). Open Educational Practices and Resources OLCOS Roadmap 2012. Salzburg, Austria: Salzburg Research Edumedia Research Group. Retrieved from www.olcos.org/cms/upload/docs/olcos_roadmap.pdf

12. Hilton III, J., Wiley, D., Stein, J., \& Johnson, A. (2010). The four "R"s of openness and ALMS analysis: frameworks for open educational resources. Open Learning, 25(1), 37-44.

13. Hodgkinson-Williams, C. (2010). Benefits and Challenges of OER for Higher Education Institutions. Presented at the Open Educational Resources (OER) Workshop for Heads of Commonwealth Universities, Cape Town, South Africa. Retrieved from http://www.col.org/SiteCollectionDocuments/OER BenefitsChallenges_presentation.pdf

14. Hodgkinson-Williams, C. (2009). Institutional Report 2 Sketching the terrain: Open educational resources for teaching and learning at the University of Cape Town (No. 2) (pp. 1-34). Cape Town, South Africa: Centre of Educational Technology, University of Cape Town. Retrieved from http://www.cet.uct.ac.za/files/file/OS\%20Institutional\%20report2\%20_\%20\%20Final\%20typeset.pdf

15. Issack, S. M. (2011). OERs in Context - Case Study of Innovation and Sustainability of Educational Practices at the University of Mauritius. European Journal of Open, Distance and E-Learning, 1-10.

16. Mitha, S. (2012). Library Report for Faculty Research Committee for Management Sciences (p. 1). Durban, South Africa: Durban University of Technology.

17. Muller, N. J., Harrison, J. E., Raju, J., \& Moodley, S. (2011, May). Discussion Paper on Open Access. Discussion paper, Durban University of Technology, KZN, South Africa.

18. Ncube, C. B. (2011). Key copyright issues in African distance education: a South African case study. Distance Education, 32(2), 269-275.

19. Sappire, I., \& Reed, Y. (2011). Collaborative design and use of open educational resources: a case study of a mathematics teacher education project in South Africa. Distance Education, 32(2), 195-211.

20. Schuwer, R., \& Mulder, F. (2009). OpenER, a Dutch initiative in Open Educational Resources. Open Learning, 24(1), 67-76.

21. The Department of Higher Education and Training, Government of the Republic of South Africa. (2012). Green Paper For Post-School Education And Training. Green Paper, Pretoria. Retrieved from www.info.gov.za/view/DownloadFileAction?id=157779

22. Wiley, D. (2006). A Brief History of OER. Discussion paper. Retrieved from http://www.oecd.org/dataoecd/19/26/36224377.pdf

23. Wiley, D., \& Gurrell, S. (2009). Context And Catalyst A decade of development.... Open Learning, 24(1), $11-21$.

24. Wilson, T. (2008). International Review of Research in Open and Distance Learning. International Review of Research in Open and Distance Learning, 9(1), 1-19.

25. Yuan, L., Macneill, S., \& Kraan, W. (2008). Open educational resources_Opportunities and challenges for higher education. Discussion paper. Retrieved from

http://wiki.cetis.ac.uk/images/6/6d/OER_Briefing_Paper_CETIS_without_recommendations_with_cover_p age.pdf 